who were induced at term had a significantly lower blood loss at delivery than a group who were left beyond the 41 st week to go into labour spontaneously. We attributed the lower blood loss after induction to the simple expedient of maintaining the oxytocin infusion for at least one hour after delivery.

One possible reason for the apparently conflicting results is that $\mathrm{Mr}$ Brinsden and $\mathrm{Mr}$ Clark and $\mathrm{Mr}$ MacKenzie are not comparing like with like. By going into spontaneous labour, patients may be demonstrating the essential "normalness" of their uterine activity whereas patients who fail to go into labour spontaneously may be declaring an abnormality of uterine function. A clue to this abnormality may come from Mr MacKenzie's own data when he shows that the use of prostaglandins prior to induction reduces the postpartum haemorrhage rate. It may well be that patients who fail to start labour spontaneously do so because of deficient prostaglandin production and that it is this failure, rather than induction itself, which is responsible for the reported increase in postpartum haemorrhage. It would seem to be essential that conclusions should be drawn from prospective controlled trials rather than from retrospective uncontrolled data.

P W HowIE

Reproductive Biology Unit,
Edinburgh EH1 2QW

Simpson Memorial Maternity Pavilion,

R A Cole

Edinburgh EH3 9E

M C Macnaughton

Glasgow Royal Maternity Hospital,

Glasgow G4 0NA ${ }^{1}$ Cole, R A, Howie, P W, and Macnaughton, M C,
Lancet, 1975, 2, 767.

\section{Concurrent steroid and rifampicin} therapy

SIR,-We read with interest the report by $\mathrm{Dr}$ W Hendrickse and others ( 3 February, p 306) of rifampicin-induced non-responsiveness to prednisolone in the nephrotic syndrome. We have recently observed a similar phenomenon in a patient being treated for tuberculous pericarditis.

A 21-year-old Pakistani presented with a 48-hour history of confusion. For about eight weeks he had been pyrexial, anorexic, and losing weight. On examination he was delirious with a temperature of $41^{\circ} \mathrm{C}$ and signs of bilateral pleural effusions and cardiac tamponade. After pericardial and pleural aspiration, chemotherapy was started with rifampicin, ethambutol, and isoniazid. Tubercle bacilli were subsequently grown from the pericardial fluid and were fully sensitive to all three drugs. Because of a continuing high fever and reaccumulation of his effusions, prednisolone was added on the 16th day of treatment and the dose adjusted to the minimum which would control the fever. From the $21 \mathrm{st}$ to the $27 \mathrm{th}$ day of treatment $30 \mathrm{mg}$ of prednisolone was effective but $25 \mathrm{mg}$ was not; thereafter control was lost and the dose of steroids had to be increased so that by the 40th day of treatment $40 \mathrm{mg}$ of prednisolone was required. It was not possible to reduce the dose of prednisolone without precipitating a considerable rise in temperature until the 79 th day of treatment. At this time the corticosteroid was gradually reduced and the patient now remains apyrexial on $10 \mathrm{mg}$ daily.

Although the patient's condition did not allow us to perform pharmacokinetic studies, we feel that the circumstantial evidence points strongly to increased metabolism of prednisolone by rifampicin-induced microsomal en- zymes. We agree with the authors that this property of rifampicin should be more widely recognised in relation to glucocorticoid therapy.

W VAN MARLE

K L WOODS

L BEELEY

Department of Therapeutics and

Clinical Pharmacology,

Queen Elizabeth Hosp
Birmingham B15 2TH

\section{Service for psychiatrically ill doctors?}

SIR,-I read with regret recently that yet another colleague had taken his life by his own hand. Surely it is an indictment of a caring profession that so many of our own members take this course of action. Doctors are vulnerable to psychiatric illness, and yet the profession has no system, either formal or informal, for offering the help to its own members which it daily offers to patients.

The profession's first priority should be the care of its own members. This need not be excessively expensive or difficult, as it should be organised and run by volunteers. The Samaritans offer a ready example of how this might be done. Regional BMA offices might, for example, keep an Ansafone which has a tape listing interested GPs, their curriculum vitae, and their bypass telephone numbers. A caller could then contact the doctor of his choice, who would have a list of agencies or psychiatrists whom he could consult. With exchange of information a worthwhile service might emerge. With this system the caller could remain anonymous throughout if that was felt to be desired.

No doubt there are many other possible systems for organising such a service. I wonder if any other doctors have views on this subject.

KENNETH HAMBLY

Stewarton, Ayrshire

\section{Clinical practice and epidemiology}

SIR,-How refreshing to read Professor E D Acheson's Adolf Streicher lecture (17 March, p 723). I would particularly like to endorse his comments on the failure of the specialty of community medicine to exploit its interest in the vital field of epidemiology.

As a former trainee in community medicine who received a first-rate postgraduate academic grounding in epidemiology, demography, and statistics, I am only too aware of how disappointing it is to experience the reality of community medicine in the National Health Service, and to be shackled by administration and local politics. As Professor Asheson pointed out, epidemiology is not a sterile subject but is the key to prevention of disease and the promotion of positive health-surely what community medicine ought to be about.

Such was my disenchantment that I moved "sideways" to occupational health. While I feel that, overall, occupational factors play a relatively small part in the aetiology of most significant diseases, I would commend occupational medicine as a possible career for anyone who wishes to develop and use epidemiological skills while retaining an active interest in clinical medicine.

G C HANCOCK

Occupational Health Service, Boots Company Limited Nottingham NG2 3AA
Difficulty in stopping lithium prophylaxis?

SIR,-The recent report of Dr D G Wilkinson (27 January, p 235) on lithium withdrawal has prompted me to write about a similar experience we had in 1976.

A woman, now aged 46 , with a history of recurrent hypomania since 1966, was put on lithium in 1972. She remained well with serum concentrations in the range of $0.5-1.0 \mathrm{mmol}$ (mEq)/l until October 1976, when she and her husband asked for the treatment to be stopped. As she had been stable for almost five years and required no hospital admission we agreed to their request. She was advised to reduce her dose by $300 \mathrm{mg}$ at intervals. Four weeks after she started to reduce lithium she became unwell and was brought into hospital by the husband. On admission she was deluded, confused with short lucid intervals, restless, incoherent, and labile in mood. The clinical picture resembled an acute confusional state, as happened in Dr Wilkinson's patient. She was put back on lithium $900 \mathrm{mg}$ daily and within a few weeks her mental state became normal again. Since then she has been maintained well with serum concentrations in the range of $0.7-0.9 \mathrm{mmol} / 1$.

M YUCE

Netherne Hospital,
Coulsdon, Surrey CR3 1YE

\section{“Doctors' orders"}

SIR,-The article by Dr D A Ellis and others (17 February, p 456) and letter from Dr J R Oakley and Mrs Patricia M McWeeny (17 March, $p$ 748) continue to interest me enormously. I wonder whether Drs Oakley and McWeeny would be prepared to put their views and comments into something more positive, and produce for all those concerned in primary care the sort of written instructions they would like to see issued when dealing with the 4-year-old child with acute otitis media.

I am sure that every medical practitioner who has given this any thought would be delighted if they could produce instructions or "doctors' orders" which are likely to cover the important and worrying complications that can arise in such a common condition as otitis media.

I hope they will rise to the challenge as befits doctors from such a unit as theirs.

Stokesley, N Yorks TS9 5DY

IAN CAPSTICK

\section{Keeping down the elephants}

SIR,-In the absence of untreated controls the results of $\mathrm{Mr} \mathrm{J} \mathrm{P}$ Pollard and others (17 March, p 707) on antibiotic prophylaxis in total hip replacement can be interpreted completely differently. Since they show that there is no difference in the infection rate in patients following three injections of cephaloridine and other patients treated with flucloxacillin for a fortnight, it could be argued that both drugs are equally ineffective in preventing infection and that any form of antibiotic prophylaxis in this condition is useless.

It rather reminds me of the story about two men going to London in a first class Pullman compartment. The first man was reading the 